\title{
"MasterChef Junior", un context rellevant per a aprendre sobre el regne vegetal a 1r d'ESO
}

Emma Cardona Roca (emma.cardona9@gmail.com) Màster de formació del professorat d'educació secundària de la UPF / UOC. Especialitat en ciències naturals.

Iván Marchán-Carvajal (imarcha2@xtec.cat) Professor de ciències a l'Institut Europa (L'Hospitalet de Llobregat) i professor associat a la Facultat d'Educació de la UB.

La proposta didàctica que es presenta es basa en una experiència didàctica desenvolupada a 1r d'ESO durant la unitat del Regne Vegetal. Treballada des d'un context proper per l'alumnat (el concurs "MasterChef Junior") pretén promoure l'aprenentatge significatiu del contingut científic, així com la rellevància dels continguts científics en la vida quotidiana.

Paraules clau: Contextualització, educació secundària, competència científica, rellevància de la ciència.

The following didactic proposal consists of a didactic experience that took part at 1 ESO during the unit of Plant Kingdom. Developed from a point of view which was very close to students: "MasterChef Junior's contest", it had different aims. For instance, promoting meaningful learning of scientific content, as well as increasing its relevance in daily life.

Keywords: Context-based education, secondary education, scientific literacy, relevance of science

\section{INTRODUCCIÓ}

L'ús de contextos a l'educació secundària es considera una estratègia didàctica potent per a l'aprenentatge científic de l'alumnat i obre una porta per afrontar el repte educatiu discutit per Sanmartí et al (2011): "l'alumnat presenta moltes dificultats per aplicar allò après a l'aula en situacions diferents a les estudiades". Per altra banda, algunes recerques recents (Stuckey et al. 2013) apunten que molts estudiants perceben les ciències com quelcom irrellevant en les seves vides presents i futures. Els autors proposen una selecció de les situacions d'aprenentatge (contextos) que tingui en compte la rellevància personal (com a adolescent amb interessos $\mathrm{i}$ inquietuds), social (com a ciutadà d'un món cada cop més global) i vocacional (com a futur treballador).

La proposta didàctica que es presenta es basa en un context (el concurs MasterChef Junior) que va promoure l'aprenentatge significatiu de contingut científic i alhora va resultar rellevant per a l'alumnat des dels tres punts de vista comentats:

- Personal: perquè els mitjans de comunicació han fet que molts joves estiguin interessats en la cuina.

- Social: la relació cuina-ciència gaudeix d'un reconeixement internacional gràcies a professionals com Ferran Adrià, a més de la importància d'una alimentació saludable ja des de ben joves.

- Vocacional: cada vegada més estudiants contemplen la cuina com una opció professional prestigiosa, per aquest motiu, estan sorgint graus i màsters sobre alimentació i ciència. (http://www.alicia.cat/). 


\section{DESCRIPCIÓ DE L’EXPERIÈNCIA DIDACTICA}

La següent proposta didàctica es va dur a terme a classe de Ciències Naturals de 1r d'ESO del centre escolar Jesuïtes de Casp (Barcelona), durant 10 sessions de classe dels mesos de febrer i març del 2015.

\section{Finalitats}

Calia dissenyar una unitat didàctica que tractés el Regne Vegetal en la seva vessant més descriptiva. Per tal d'evitar-ne la memorització i afavorir-ne l'aprenentatge significatiu es va voler aportar una innovació metodològica a l'aula. Es treballaria el regne vegetal des d'un context proper a l'alumnat a partir d'investigar quins vegetals tenen interès culinari, quines parts s'aprofiten, etc. Per a fer-ho serien convidats a participar en el concurs televisiu "MasterChef Junior" (Figura 1) on se'ls demanaria crear uns plats per equips amb ingredients exclusivament vegetals.

\section{Necessitats}

Durant la fase d'observació del Pràcticum, s'evidenciava com alguns alumnes tenien dificultats per utilitzar els conceptes apresos en una assignatura quan se'ls hi exigia des d'una altre. Hi havia una manca de connexió interdisciplinària generalitzada. Paral•lelament, en un altre nivell (2 d'ESO) s'iniciava una setmana de treball per projectes. Una metodologia totalment diferent al que era habitual però amb uns resultats molt gratificants i esperançadors tant per professors com alumnat.

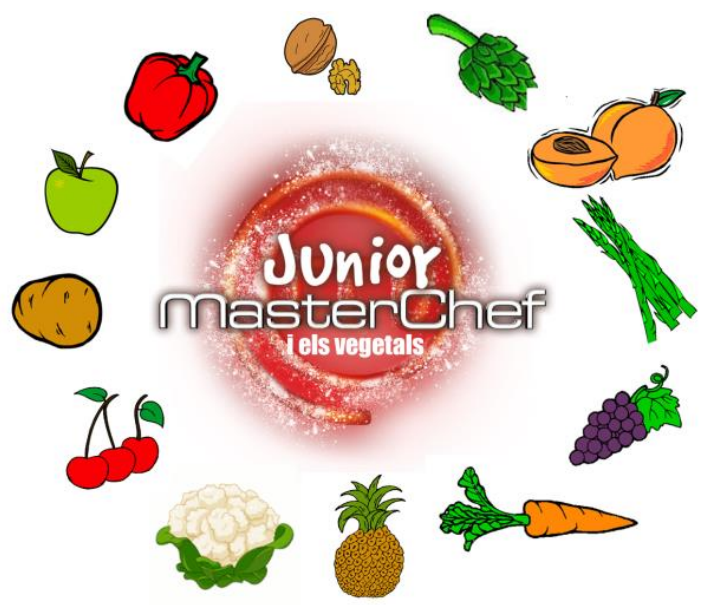

Figura 1. "MasterChef Junior i els vegetals" com a context de partida per a l'aprenentatge del regne vegetal a 1 d'ESO des d'una perspectiva més rellevant per a l'alumnat.

Per altra banda, la majoria de centres encara treballen amb una orientació de l'educació força centrada en els continguts i no en les competències, tot i que aquestes últimes requereixen els continguts. Les pautes marcades per PISA pel 2015 es descriuen a la Figura 2 (OCDE, 2013). La hipòtesi de treball és que possiblement s'obtindria una millor qualificació en les proves que mesuren la competència científica si en el disseny d'unitats didàctiques es tingués en compte que la competència integra contextos, coneixements i actituds.

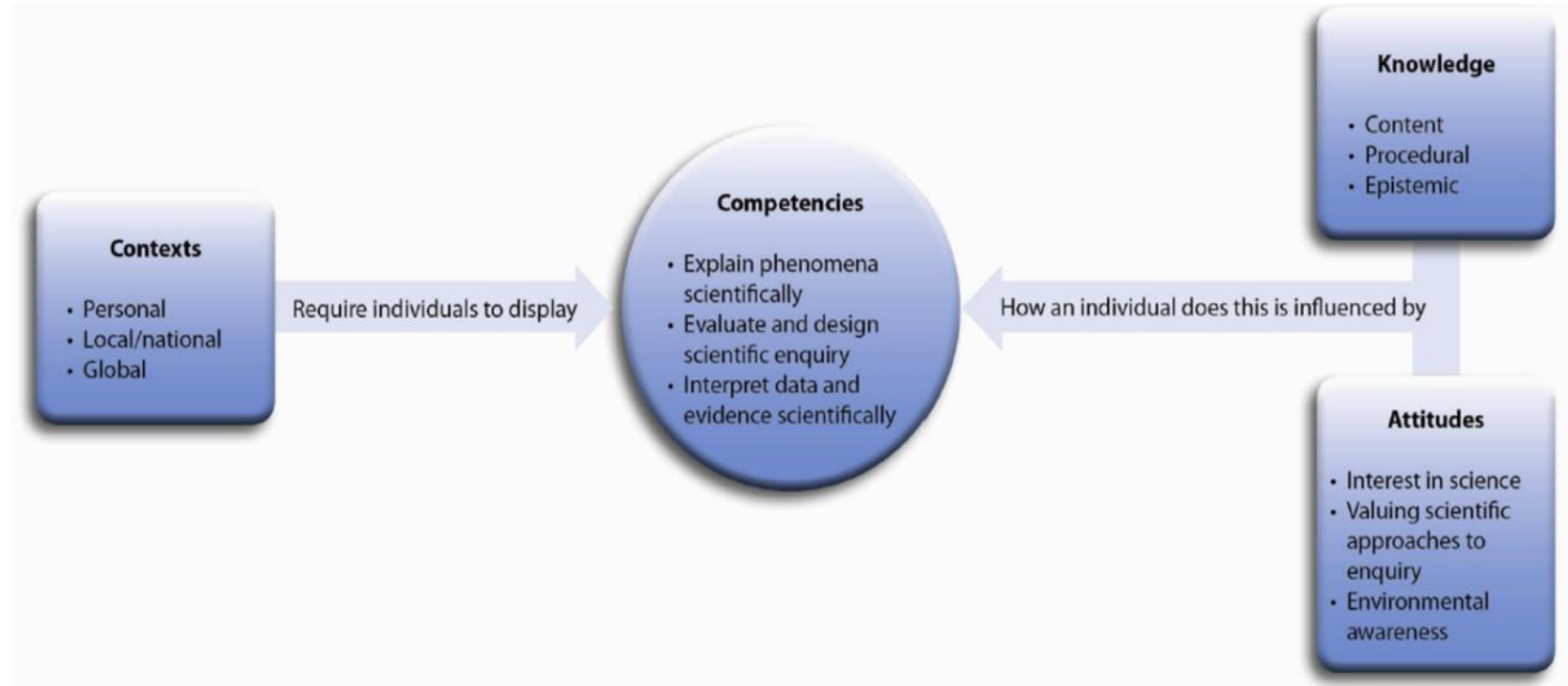

Figura 2. PISA 2015: Aspectes del marc teòric en que basa la valoració de la competència científica (OCDE, 2013). 


\section{Oportunitats}

Precisament en els primers cursos de l'educació secundària obligatòria hi conflueixen diferents necessitats. En primer lloc, (1) els alumnes procedents de la primària comencen un procés d'adaptació cap a una nova etapa educativa, i és doncs l'oportunitat perfecta per a implantar una nova metodologia. Alhora, (2) les tipologies d'alumnat són de caire molt divers (alumnat d'altes capacitats, alumnat menys acadèmic, diferents procedències - culturals, familiars, etc.-) i cal trobar aquell ritme de treball que s'adapti a les diferents necessitats individuals. Tenint en compte que aprendre implica construir significats sobre els continguts escolars i atribuir-los un sentit, la contextualització esdevé un oportunitat metodològica idònia per a que gran part de l'alumnat es senti motivat a fer-ho (Caamaño, 2005).

Altrament, l'ensenyament basat en el context pot ser una eina potent per a fomentar la capacitat de transferència (Sanmartí et al, 2011), ja que els alumnes aprenen des d'un bon principi que el coneixement científic impregna la vida quotidiana, per tant, si les activitats que es fan a l'aula s'assemblen a les que es trobaran fora de l'aula, s'està contribuint a que l'alumnat doni sentit al coneixement científic més enllà de l'escola i sigui capaç de mobilitzar els sabers quan li calgui.

\section{Intervenció a l'aula}

El context d'aprenentatge va ser presentat a l'alumnat el primer dia. Tots els alumnes van ser convidats, mitjançant una carta, a participar en la prova final (pràctica de laboratori interdisciplinària) en la qual haurien d'assolir un repte culinari: dissenyar per equips un plat original amb ingredients d'origen exclusivament vegetal. Per tal d'obtenir uns bons resultats era necessària una bona formació en el regne vegetal, el qual lligava amb tot el temari que es desenvoluparia al llarg de les 10 sessions programades. La metodologia utilitzada inclouria 7 sessions a l'aula i 3 sessions pràctiques al laboratori.

Els objectius d'aprenentatge van ser presentats el primer dia de classe en format de llista (adjunt en el dossier de classe) com a "criteri del bon participant". Mitjançant aquesta eina es pretenia donar a conèixer $\mathrm{i}$, per tant, compartir les fites del procés d'ensenyament-aprenentatge del període de classes. Els alumnes aprendrien "què entenem per vegetal" i quines són les seves característiques principals, quina estructura presenten a nivell microscòpic (treballant el concepte de cèl•lula i la utilitat del microscopi) i macroscòpic (arrel, tija, fulles, flor, fruit, llavor). Alhora, es presentaria una de les classificacions generals del regne més acceptades: briòfits, pteridòfits i espermatòfits (gimnospermes i angiospermes), introduint l'eina dels mapes conceptuals per a comprendre com s'havia arribat a definir un criteri classificador. Tots aquests conceptes i procediments, quedarien justificats amb la necessitat de conèixer "quins grups de vegetals mengem i quins no tenen interès culinari". Així doncs, es pretenia que els alumnes reflexionessin, a través dels nous aprenentatges, què aprofitem de cada vegetal o quins vegetals són comestibles o no.

A l'aula, els alumnes van treballar amb el suport d'un dossier de classe entregat el primer dia i recollit el darrer per a ser avaluat. Cada classe es va impartir amb un suport powerpoint que posteriorment es penjaria en el "sites". Les activitats plantejades van ser molt diverses: treball individual i grupal (grup d'experts i cooperatiu), breu exposició individual d'un ingredient vegetal amb coavaluació dels companys, lectura comprensiva, ús de mapes conceptuals, etc. A les pràctiques experimentals, es va estimular l'observació crítica, l'ús d'aparells com la lupa binocular i la balança. També es van incloure exercicis amb conceptes de matemàtiques (canvis d'unitats i operacions bàsiques) i d'anglès (vocabulari) per a fomentar el treball interdisciplinari. La Taula 1 recull l'organització principal de la unitat didàctica. L'avaluació va ser de tipus formativa. Com a fita final havien de dissenyar un plat entre els membres del grup en la darrera sessió de laboratori (Figura 3). En aquesta pràctica van identificar un gran ventall de vegetals (prèviament presentats en les exposicions orals), i van seleccionar els corresponents pel seu plat, els van pesar $i$ van valorar la quantitat necessària per a un nombre determinat de comensals i la interpretació d'una taula de dades reals sobre la producció agrícola catalana.

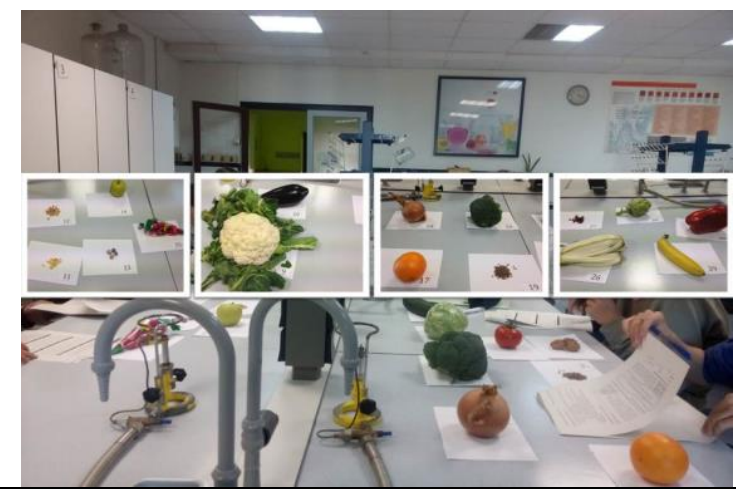

Figura 3. Pràctica 3 "Posem-ho tot a punt!" on els alumnes havien de dissenyar els seus plats vegetals com a participants del concurs televisiu "MasterChef Junior". 


\begin{tabular}{|c|c|c|}
\hline $1(\mathrm{AULA})$ & $\begin{array}{l}\text { Presentació del context } \\
\text { d'aprenentatge i idees prèvies }\end{array}$ & $\begin{array}{l}\text { Invitació al concurs (carta). Exposició d'objectius i criteri d'avaluació. Test } \\
\text { d'idees prèvies sobre característiques del regne vegetal (repàs de conceptes } \\
\text { bàsics entre tots). }\end{array}$ \\
\hline 2 (AULA) & $\begin{array}{l}\text { Estructura vegetal microscòpica: } \\
\text { la cèll|lula vegetal (vs. cèl'lula } \\
\text { animal) }\end{array}$ & $\begin{array}{l}\text { Repartició dels diferents orgànuls. Cada petit grup investiga la funció } \\
\text { (internet) i el representa. Posada en comú a la pissarra ("contrucció d'una } \\
\text { cèl-lula vegetal gegant"). }\end{array}$ \\
\hline \multirow{3}{*}{$3(\mathrm{LAB})$} & \multirow{3}{*}{$\begin{array}{l}\text { PRÀCTICA 1: Estructura vegetal } \\
\text { macroscòpica (pràctica } \\
\text { rotatòria) }\end{array}$} & $\begin{array}{l}\text { Taula A: Observació dels vasos conductors -relació estructura i alçada- (api } \\
\text { amb vasos tenyits amb tinta). }\end{array}$ \\
\hline & & $\begin{array}{l}\text { Taula B: Dibuixar una planta sencera (lliri). Identificar les parts, descriure’n } \\
\text { característiques i relacionar-ho amb la funció. }\end{array}$ \\
\hline & & $\begin{array}{l}\text { Taula C: Observació d'una flor hermafrodita (lliri o tulipa) amb la lupa } \\
\text { binocular. }\end{array}$ \\
\hline \multirow[b]{2}{*}{4 (AULA) } & dels vegetals & $\begin{array}{l}\text { Construcció (entre tots) d'un mapa conceptual mitjançant l'observació de } \\
\text { fotos. }\end{array}$ \\
\hline & Briòfits i & $\begin{array}{l}\text { Treball per grups (4): 1r) Experts (estructura i reproducció de briòfits } 0 \\
\text { pteridòfits); } 2 n \text { ) Cooperatiu: activitat breu d'aplicació. }\end{array}$ \\
\hline \multirow[b]{2}{*}{$5(\mathrm{AULA})$} & $\begin{array}{l}\text { Classific } \\
\text { (continu }\end{array}$ & $\begin{array}{l}\text { Finalització del mapa conceptual fins a la distinció dels espermatòfits. } \\
\text { També mitjançant l'observació de fotografies. }\end{array}$ \\
\hline & Espermatòfits & $\begin{array}{l}\text { Discussió dels espermatòfits que coneixen (idees prèvies). Explicació de la } \\
\text { tasca individual (creació d'una diapositiva que caldrà exposar. Cada alumne } \\
\text { investiga un ingredient vegetal -proporcionat pel professor- i en detalla la } \\
\text { informació acordada. }\end{array}$ \\
\hline $6(\mathrm{LAB})$ & $\begin{array}{l}\text { PRẢCTICA 2: Observació de } \\
\text { molses i falgueres }\end{array}$ & $\begin{array}{l}\text { Observació de molses i falgueres mitjançant l'ús de la lupa binocular. } \\
\text { Identificació i representació (guió) de les parts estudiades a l'aula. }\end{array}$ \\
\hline $\begin{array}{l}7 \text { i } 8 \\
\text { (AULA) }\end{array}$ & Espermatòfits comestibles & $\begin{array}{l}\text { Exposicions orals, ordenades sistemàticament segons si l'ingredient } \\
\text { correspon a: arrel, tija, fulla, flor, fruit, llavor. Coavaluació de les exposicions. }\end{array}$ \\
\hline \multirow[b]{2}{*}{$9(\mathrm{LAB})$} & \multirow{2}{*}{$\begin{array}{l}\text { PRÀCTICA 3: Posada a punt } \\
\text { dels plats MasterChef (pràctica } \\
\text { rotatòria i interdisciplinària) }\end{array}$} & $\begin{array}{l}\text { Taula A: Identificació de vegetals comestibles (ingredients prèviament } \\
\text { estudiats a les exposicions): anomenar i identificar la part (en català i anglès) }\end{array}$ \\
\hline & & $\begin{array}{l}\text { Taula B: Recepta. Elecció de } 5 \text { ingredients de la taula A. Pesada (balança), } \\
\text { càlcul de quantitats necessàries ( } \mathrm{g} \text { i kg). Lectura i interpretació d'una taula } \\
\text { de dades reals sobre la producció agrícola catalana. }\end{array}$ \\
\hline $\begin{array}{l}10 \\
(\mathrm{AULA})\end{array}$ & Darrera sessió (Enquesta i Tast) & $\begin{array}{l}\text { Realització de l'enquesta de valoració (google forms) i tast dels plats creats } \\
\text { (tasca opcional). }\end{array}$ \\
\hline
\end{tabular}

Taula 1. Resum de la unitat didàctica. D'esquerra a dreta: número de sessió, conceptes treballats, activitats proposades.

\section{Resultats}

El darrer dia de classe es va demanar a l'alumnat respondre una enquesta de valoració final (preguntes obertes i tancades). La percepció general de l'alumnat va ser satisfactòria i a continuació es destaquen algunes dades significatives:

- El treball competencial va ser valorat d'utilitat pel seu futur sobretot en aquelles competències comunicatives (treball en grup, exposició oral), en contraposició a les metodològiques (matemàtiques, aprendre a aprendre) que els van passar més desapercebudes.

- El context els va permetre establir més fàcilment una connexió entre la ciència escolar i les seves vides quotidianes, afavorint la rellevància del contingut en les tres dimensions comentades (personal, social i vocacional).

- La nova metodologia va suposar un increment petit de la percepció de dificultat $(23,33 \%)$, i només un $6,66 \%$ va trobar a faltar la classe tradicional. Aquest fet es pot atribuir a una actitud conservadora i no tant a que el context fes que la unitat fos més complexa.

- Un $95 \%$ de l'alumnat, sense diferències significatives entre nois i noies, van afirmar que les classes contextualitzades els havien motivat més.

- Quan es va preguntar a l'alumnat si triarien una matèria optativa de ciències a $4 \mathrm{t}$ d'ESO, aquells alumnes que van descartar escollir-la, ho van fer per motius de desinterès (30\%) 0 de dificultat $(16,67 \%)$. A més, un $16,67 \%$ dels enquestats van mostrar-se indecisos. Com a 
docents se'ns dóna la oportunitat de promocionar el balanç cap a l'interès de les ciències, per exemple, mitjançant la contextualització.

- Als alumnes els agradaria treballar les ciències naturals: contextualitzades (60\%), treballant en grup $(13,33 \%)$ o bé mitjançant els jocs.

\section{VALORACIONS I REFLEXIONS}

Tot i els resultats positius de l'experiència didàctica, cal tenir en compte que la contextualització també té les seves limitacions:

- Requereix molt més temps d'intervenció pel qual es veu minvat el contingut a ensenyar. És necessari prioritzar-ne les idees clau.

- Una metodologia basada en la contextualització comporta la fragmentació dels continguts, en comparació a l'exposició ordenada d'una lliçó magistral. En conseqüència, quan el context és aplicat al llarg de tot un curs les activitats de síntesi i estructuració són més necessàries encara.

- Seria interessant disposar d'un instrument de recollida de dades estandarditzat per a poder comparar les diferents experiències en contextualització, sobretot per a comprovar si l'alumnat que no ha treballat de manera contextualitzada té la mateixa capacitat d'aplicar el coneixement científic en noves situacions, diferents del Masterchef. És a dir, evidenciar si contextualitzar promou la capacitat de transferir el coneixement més enllà de l'aula.

- Cada context educatiu és un món i per tant els seus efectes també. És a dir, en un altra escola, un altre nivell, un altre any o quan el contingut és molt més abstracte (per exemple, el model de partícules) no necessàriament es trobarien els mateixos resultats.

- Caldria lligar aquesta unitat amb el model teòric d'ésser viu treballat a altres unitats per a promoure una interrelació entre les idees clau al llarg de l'etapa de secundària obligatòria.

- Una sortida fora del centre podria suposar un valor afegit al context treballat, per exemple a un jardí botànic o a un centre sobre alimentació i ciència.

\section{MATERIALS}

https://drive.google.com/file/d/OB13uFtHxdWqN RDd2OTE2V1Jlb2M/view?usp=sharing

\section{AGRAIIMENTS}

Aquest article recull els principals resultats $i$ reflexions obtingudes en el Treball de Fi de Màster de formació del professorat d'educació secundària a la UPF/UOC en l'especialitat de Ciències Naturals. L'autora agraeix la confiança, energia, dedicació i suport en tot moment del seu tutor del TFM, Iván Marchán. Agraeix també l'ajuda, paciència i consells d'en Marcel Costa com a tutor de la UD. Així mateix l'autora vol mostrar el seu agraïment al centre dels Jesuïtes de Casp, però en especial a la Carla Adrián, mentora del centre i professora de la classe d'estudi, per haver acceptat la proposta didàctica des del primer moment. Permetre que un futur docent posi a prova tot allò que ha après durant l'especialització és la millor oportunitat per a seguir aprenent.

Proposta realitzada en el marc del grup LIEC (Llenguatge i Ensenyament de les Ciències), grup d'investigació consolidat (ref. 2014SGR1492) per AGAUR (Agència de Gestió d'Ajuts Universitaris i de Recerca) i finançat per la Dirección General de Investigación, Ministerio de Educación y Ciencia (EDU2012-38022-C02-02)

\section{Bibliografia}

BENNETT, J., LUBBEN, F., I HOGARTH, S. (2007). Bringing science to life: A synthesis of the research evidence on the effects of context-based and STS approaches to science teaching. ScienceEducation, 91 (3), 347-370.

CAAMAÑO, A. (2005). Contextualizar la ciencia. Una necesidad en el nuevo currículo de ciencias. Alambique. Didáctica de las Ciencias Experimentales, 46, 5-8.

OCDE (2013). PISA 2015. Draft Science Framework. Recuperat el 18 de Juny de 2015 de

http://www.oecd.org/pisa/pisaproducts/pisa2015 draftframeworks.

SANMARTÍ, N., BURGOA, B. I NUÑO, T. (2011). Por qué el alumnado tiene dificultad para utilizar sus conocimientos científicos escolares en situaciones cotidianas?. Alambique, 67, 62-69.

STUCKEY, M. , HOFSTEIN A., MAMLOKNAAMAN, R I EILKS I. (2013) The meaning of 'relevance' in science education and its implications for the science curriculum, Studies in Science Education, 49:1, 1-34. 